\title{
Vulnerabilities to Petty Corruption in Ghana's Healthcare System: An Ethnographic Study
}

\author{
George Ayuune Akeliwira \\ Centre for Empirical Research in Economics and Behavioral Sciences, University of Erfurt. \\ Donaustrasse 34, 99089 Erfurt, Germany \\ E-mail: george.akeliwira.01@uni-erfurt.de
}

\begin{abstract}
Corruption continues to be a major issue of global concern and discussions on the issue have escalated over the past two decades, prompting the Bretton Woods institutions and the donor community to tie development assistance to governance indicators. Accordingly, there is a growing shift among the research community toward a disaggregated corruption research due to the beguiling assumption that a reduction in grand corruption would have a knock-on effect on petty corruption. Ghana has a multiplicity of laws and policies aimed at tackling the menace of corruption in public service. Notwithstanding, corruption continues to be a major hindrance to national development efforts. Indeed, the country has been performing below average in the global Corruption Perception Index by Transparency International in the past decade. The study examines the drivers of petty corruption in the health sector through a field survey comprising two hundred respondents in five major referral hospitals across five regions, combined with key informant interviews and secondary sources. It finds informal payments as the main driver of petty corruption in the health sector, which is sustained by social norms and the desire to obtain preferential treatment occasioned by social pressures. The study discusses the implication for interventions such as the national health insurance scheme, which was designed to protect vulnerable groups against out-of-pocket payments for healthcare and concludes with directions for future research.
\end{abstract}

Key words: Ghana, Corruption, Healthcare, Informal Payments, Value systems, Health insurance

DOI: $10.7176 /$ PPAR/12-1-05

Publication date: February $28^{\text {th }} 2022$

\subsection{Research Problem}

Corruption continues to be a major issue of global concern and discussions on the issue have escalated over the past two decades, prompting the Bretton Woods institutions and the donor community as a whole to tie development assistance to governance indicators, of which corruption is a key component. The scourge of corruption in the last twenty years has also led to the formation of global anti-corruption movements such as Transparency International. Indeed, the impact of corruption on democratic stability and development efforts is so severe that regional bodies such as the European Union regularly monitor corruption in their member countries and even tie funding to performance on governance indicators (Fazekas et al. 2013a). Global data with respect to the impact of corruption in healthcare is scarce. However, countries face significant risk, as an approximated value of $\$ 455$ billion of the $\$ 7.35$ trillion spent on healthcare annually worldwide is lost each year to fraud and corruption (Teremetskyi et al. 2020a).

Although significant work has been done on the causes and consequences of corruption, it has not led to significant reductions globally based on the annual Corruption Perception Index survey by Transparency International. This therefore calls for the need to disaggregate and acknowledge the varieties of corruption and sector specifics in order to fully appreciate their nature, causes and impacts (Matukhno, 2014a).

Ghana, as in many other developing countries is faced with tremendous challenges in the provision of public service including healthcare. Aside from the traditional problems of shortage of health professionals, inadequate health facilities and other teething challenges peculiar to the healthcare systems of many developing countries, a major problem in Ghana's health sector is corruption. The Ministry of Health receives a minimum of 20 percent budgetary allocations every year. Aside from that, the health sector is a major recipient of financial and logistical support from intergovernmental organizations such as the World Health Organization and other development partners. Furthermore, the government in 2003 introduced a national health insurance policy with two broad objectives. First, to make the cost of healthcare affordable and to enhance transparency in the provision of health services in the country. ${ }^{1}$ Thus, apart from education, the health sector receives the highest funding among all public sectors in the country.

\footnotetext{
${ }^{1}$ The primary objective of the scheme is to ensure financial access to basic healthcare services for residents without having to pay out-of-pocket at the point of healthcare service delivery. The National Health Insurance Scheme has become an integral part of Ghana's strategy to move towards universal health coverage. Retrieved from NHIS Review
} 
However, it appears that most of these resources allocated to the health sector are lost to corruption through theft, embezzlement and other financial malfeasance. Admittedly, corruption in Ghana occurs in almost all spheres of national life. However, the phenomenon seems to be very rampant in the health sector, according to studies. Example, a study commissioned by the World Bank in 2010 called "Quite Corruption", actually placed the healthcare system of Ghana as the second most corrupt in relation to the management of resources in health systems in Africa. ${ }^{2}$

In light of this, the study aims to achieve two main objectives, to establish which aspect of the healthcare system in Ghana is too prone to corruption and to analyze the factors that make that particular aspect too vulnerable to corruption and what can be done to curb the current scourge. The relevance of the study is defined by the government's commitment to minimize corruption in public service as the country continues to perform below average in the CPI as well as realize the Sustainable Development Goals (SDGs), especially target 16.5 of goal 16 that seeks substantial reduction in corruption and bribery "in all their forms".

\subsection{Theoretical Overview}

The objective of the study is to establish the lead cause of petty corruption in Ghana's healthcare system and examine the factors fueling it. To provide a context for explaining the theoretical models concerning the nexus between healthcare systems and corruption, the study seeks to answer the following two main questions.

- What aspect of the healthcare system is too prone to corruption?

- What factors make that aspect of the healthcare system too vulnerable to corruption?

The importance of a research question in realizing the objective(s) of a study cannot be overemphasized. As succinctly explained by Tranfield et al. (2003), the relevance of a study is dependent on the research question, since that partly determines its eligibility for inclusion and exclusion or the relevance and irrelevance of the study respectively. Therefore, in order to situate the questions in the right context in terms of the theoretical models and the objectives, the study applied the CIMO (Context, Intervention, Mechanism, and Outcome) logic to formulate the research question(s).

According to the CIMO analytical framework, a research question is formulated in a specific context (C), which triggers an intervention $(\mathrm{I})$, initiated to generate mechanisms $(\mathrm{M})$ to deliver the expected outcomes (O), (Pilbeam et al. 2012). In the specific case of this study, the context is Ghana, which is a developing country, the intervention is healthcare, the mechanism is corruption and the outcome is an efficient and corruption-free healthcare system, capable of meeting target 16.5 of the Sustainable Development Goals, which seeks a substantial reduction in corruption and bribery "in all their forms". Figure1 summarizes the CIMO logic and its application to the current research question(s).

Fig.1

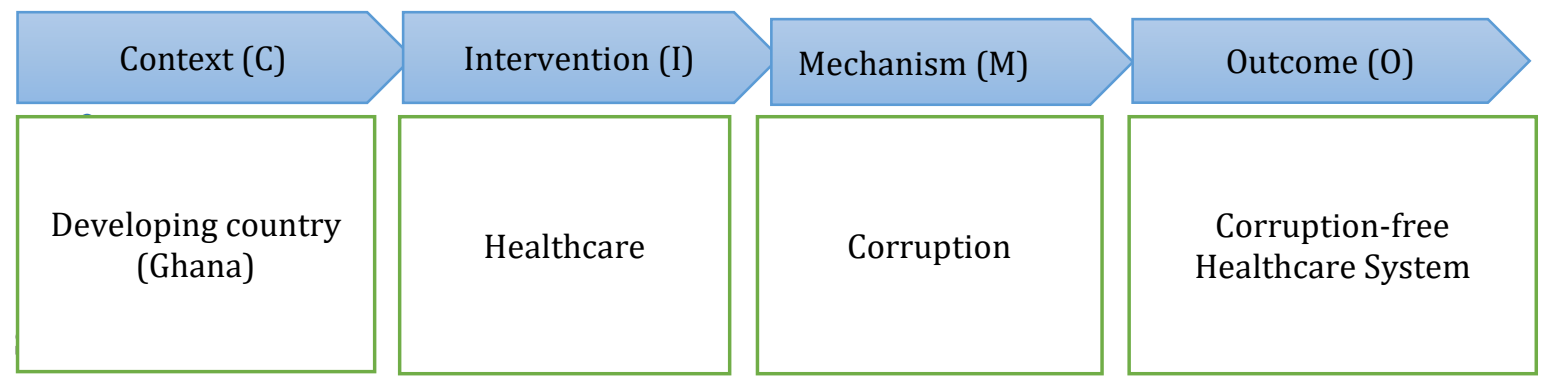

Source: Author (2022)

\subsection{Institutional Corruption}

Normative institutionalists' conception of corruption does not in essence deviate fundamentally from the contemporary and popular definition of corruption, which is the "abuse of public office for private gain" (Bussel, 2012). Nonetheless, institutional corruption theorists believe that corruption is not just exemplified by bribery and or offenses considered illegal, nor a structural issue common in many developing countries (Rose-Ackerman and

\footnotetext{
${ }^{2}$ A report by the World Bank called "Quiet Corruption" has revealed that 95 percent of resources allocated to the health sector in Ghana was diverted into the pockets of individuals. Retrieved from Ghana's health sector ranked 2nd most corrupt (modernghana.com)
} 
Palifka, 2016). For these theorists, the attention is not the corruption of institutions but the distinctive ways in which institutions can be corrupted. According to these normative institutionalists, corruption is distinctively integral to the institution in three main ways. First, it is equivocal; thus, corruption benefits the institution while undermining it simultaneously, therefore, corruption exploits legitimate institutional practices for which alternatives must be found if that institution is to function well.

Secondly, institutional corruption is impersonal; in other words, "the individual agents of corruption act in institutional roles and do not have the corrupt motives that characterize agents who participate in quid pro quo exchanges" (Thompson, 2018a). Example, in competitive democratic elections, politicians who accept campaign contributions and render service or favors for their constituents, do so in their own political interest and at the same time promote the competitive and other values of the democratic process. The final element of institutional corruption according to Thompson (2018b) is that it is generalizable, thus it can be found not only in government but also in many other private institutions.

In essence, the original focus of institutional corruption theorists on political institutions have stimulated other scholars to examine institutional corruption beyond politics to other spheres including sports, the pharmaceuticals, universities, hospitals, banks, and many others. The advantage with the institutional model of corruption is that it brings out more clearly, how corruption is related to the theory and practice of institutions and further connects corruption to principles of democratic theory. Fundamentally, a major takeaway from the model is its support for the idea that there is the need to broaden the reach of legal and ethical regulation within institutions in order to minimize incidence of corruption.

\subsubsection{Petty and Grand Corruption}

Corruption can also be modeled as either "Grand or Petty". Grand corruption is defined as corruption at the 'high levels' of a political system. It relates to large-sum, one-time payments to higher-level officials involving public contracts, laws, policies and judicial decisions (Amundsen, 1999a); (Lambsdorff, 2007a). Grand corruption occurs in the form of infrequent transactions for large sums of money and it takes place within higher-level institutions, and takes the form of embezzlement at the state-level, large bribes, fraud, high-level of favoritism and nepotism (Matukhno, 2014b). Grant corruption takes place mostly in the spheres of public procurement. In this context, it refers to the allocation of performance of public procurement contracts by circumventing prior explicit rules and principles of good public procurement in order to benefit a closed network while denying access to all others (Fazekas et al. 2013b).

On the other hand, petty corruption is defined as small payments to public officials that citizens give in the process of everyday affairs (Rose-Ackerman, 1999a). Petty corruption, otherwise called administrative corruption can also be defined as bribes to influence policy implementation (World Bank, 2000). The significant difference between petty and grand corruption rests on the quantum or value of the exchange as well as the recipients involved. For example, whereas grand corruption is linked to high profile officials including politicians, petty corruption is associated with administrative-level or low-level public servants. Furthermore, a clearer distinction between grand and petty corruption is that, while grand corruption is associated with 'high levels' of a political system, petty corruption is the small-scale corruption that takes place at the lower echelons of society (Rose-Ackerman, 1999b); (Amundsen, 1999b). Furthermore, whereas grand corruption involves widespread syndicates and several millions of monies, petty corruption involves smaller amounts of money described in various terms including 'grease money' that is meant to facilitate the delivery of goods and services (Medalla \& Balboa, 2006).

Finally, whereas grand corruption has the capacity to alter laws, policies and even judicial decisions and ofteninvolving vast amounts of money, petty corruption on the other hand, does not have the potency and capacity to influence policy making and involves small amounts of money per transaction (Lambsdorff, 2007b); (Jain, 2001). The importance of classifying corruption as either grand or petty is that it enables policy makers to evaluate corruption impacts on sustainable development and the appropriate strategies and policies needed to tackle it.

\subsubsection{Drivers of Corruption}

Several studies have tried to establish the nature and type of corruption that persists in the health sector, particularly in developing countries. According to Lewis (2006), in assessing corruption in the health sector, one has to analyze the roles and relationships among the different players to ascertain or identify potential abuses that are likely to occur as well as the functions of the health care delivery process to unearth potential abuses that can occur at each step. In low to middle-income countries in particular, corruption in healthcare is driven by poor or non-existent regulation, over regulation, lack of accountability, low salaries and greater demand than availability of supply of 
services or other products ${ }^{3}$. Further, the risks of corruption in healthcare are also influenced by several organizational factors. For example, Savedoff and Hussmann (2006a) explain that the health sector is particularly susceptible and vulnerable to corruption due to uncertainties in the sector. Among the uncertainties include the demand for services such as the inability to predict who would fall ill, when the person would fall ill and what would be the illness as well as what the person would need.

It is argued that the hallmarks of corruption in the health sector are characterized by bribes and kickbacks that can be paid to individuals and firms to procure contracts, leases or licenses, as well as the construction of health facilities, supply of drugs, goods and services (Chattopadhyay, 2013a). Furthermore, corruption is manifested in the health sector through prefix or 'rigging' of the bidding process as well as manipulating and falsifying records in order to modify evidence, so that records will appear to have complied with the norms and standards of regulatory institutions. Chattopadhyay (2013b) adds that, theft and embezzlement contribute significantly as far as corruption in healthcare systems is concerned. It occurs by way of theft of public assets and goods such as instruments and drugs by individuals for sale or personal use.

The risks of corruption in healthcare systems is also heightened by the fact that there is a web of dispersed actors operating in the health sector including regulators, payers, providers, consumers and suppliers interacting in various complex ways. This asymmetric relationship among these actors according to Savedoff and Hussmann (2006b) makes it difficult to identify and control for diverging interests. Figurel below explains the relationship among the various actors in the health sector. The analysis points to the fact that the several actors and players in healthcare systems make it extremely difficult to monitor and enforce regulations that promote transparency in the sector.

Fig. 2 Examples of corrupt practices among different health sector players

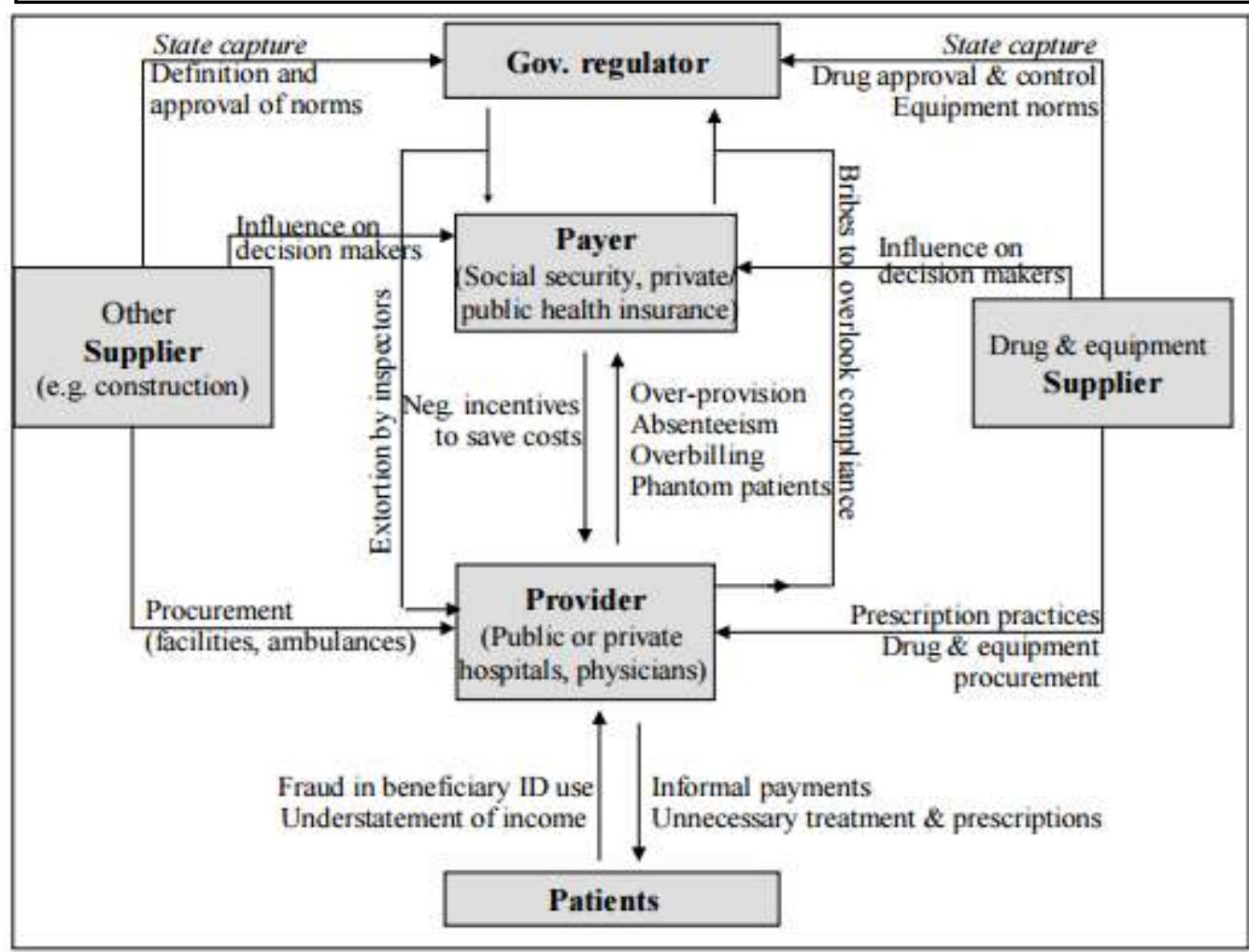

Source: Savedoff and Hussmann (2006)

The complicated nature of the healthcare system where decisions and roles are divided among the many actors make it difficult to promote transparency and to hold people accountable (Hussmann, 2011). In addition, one of

3United Nations Development Programme (2011). Fighting corruption in the health sector methods, tools and good practices. www.undp.org/content/dam/undp/library/Democratic\%20Governance/IP/Anticorruption\%20Methods\%20and\%20 Tools $\% 20$ in $\% 20$ Health $\% 20$ Lo $\% 20$ Res $\% 20$ final.pdf 
the factors that makes the health sector very vulnerable to corruption is the extent to which private health providers are entrusted with important public roles and the large amount of public money allocated to health spending in many countries, (Vian, 2008a). Another opportunity space that increases risks of corruption in healthcare systems is the provision of health infrastructure. The construction of hospital infrastructure, high tech equipment and the increasing arsenal of drugs needed for treatment combined with a powerful market of vendors and pharmaceutical companies all present risks of bribery and conflict of interest in the health sector (Vian, 2008b).

According to Transparency International, corruption in the health sector is essentially a matter of life and death situation and the poor are often the worst affected. Medical staff for example can charge unofficial fees before they attend to patients as well as demand bribes for medications, which are ordinarily supposed to be free. This attitude gives space to patients who have the capacity to pay the bribes to 'queue-jump' and have quick access to medical care at the expense of others.

\subsection{Methodology}

The study relied on a descriptive qualitative approach to study the drivers of petty corruption in the healthcare system of Ghana. Qualitative approach was most appropriate because it allowed for in-depth interviews, which is appropriate for documenting expenditure on government services that are supposed to be offered free of charge (McKee \& Balabanova, 2002). Qualitative tools also help to define the pressures and social norms related to corruption and the detailed pathways by which corruption takes place (Vian, 2008b). Indeed, a qualitative method was successfully used to assess corruption in health in Mozambique and Cape Verde, which sought to understand pressures behind the pilfering of public supplies of drugs by government employees (Ferrinho et al. 2004).

\subsection{Sampling and Data Collection}

Data collection comprised three formats; face-to-face semi-structured interviews, key informant interviews and content analysis of media and other secondary sources. Face-to-face interviews were conducted in two phases, (phase I \& II). The outcome of survey phase I informed the design of the content of the questionnaire for survey phase II. The survey had a sample size of 200 respondents and took place in the Bolgatanga regional hospital from the Upper East, the Korle-Bu teaching hospital from Greater Accra, the Cape Coast regional hospital in the Central Region and the Tamale teaching hospital from the Northern Region. The survey was conducted in five regions and in five major referral hospitals. However, the number of respondents selected for the survey was not uniform. In this case, Greater Accra and Ashanti regions had the highest number of fifty participants, followed by the Northern region with forty while Upper East and Central regions had thirty people participating in the survey. Table 1 below provides a breakdown of the regional representation of the survey participants. In all, two hundred people participated in the survey.

Table 1

\begin{tabular}{|c|c|c|}
\hline \multicolumn{2}{|c|}{ Distribution of Survey Participants } & \\
\hline Name of Region and Hospital & Number of Participants & \\
\hline Greater Accra/Korle - Bu & 50 & \\
\hline Ashanti/Komfo Anokye & 50 & \\
\hline $\begin{array}{l}\text { Northern/Tamale } \\
\text { Teaching Hospital }\end{array}$ & 40 & \\
\hline $\begin{array}{l}\text { Upper East/Central } \\
\text { Hospital }\end{array}$ & 30 & \\
\hline $\begin{array}{l}\text { Central/ Cape Coast } \\
\text { Teaching Hospital }\end{array}$ & 30 & \\
\hline Total & 200 & \\
\hline
\end{tabular}

Source: Author (2022)

In terms of the demographic composition of the respondents, males constituted $51.6 \%$ while $48.4 \%$ were females, those below the age of 40 was $64.1 \%$ with the rest being more than 40 years. In terms of religion, the majority (74.01\%) of respondents were Christians followed by Muslims with (20.33\%), Traditionalists (3.06\%), Nonreligious $(2.57 \%)$ and others $(0.4 \%)$. For education, close to $70 \%$ of respondents have had some level of education 
with the majority having basic or secondary school level education. For income distribution, sixty-one percent earned below GHS 500 monthly; 25.5 percent of respondents earned between GHS 501 - GHS 1,000; 9.7 percent earned between 1,001-2,000; 3.2 percent earned between 2001-3,000; and 0.18 percent earned GHS 4,000 and above monthly. Finally, on employment, an overwhelming majority of respondents (61.7\%) was self-employed; 14.9 percent were employed in the formal sector; 20.6 percent were unemployed and the rest either were retired or did not disclose their employment status.

The first question-required respondents to select only one out of five options that a respondent believed was the main driver of corruption in healthcare. The thematic areas of health sector corruption that informed the content of the first question was based on a thorough review of the theoretical models on health sector corruption in the context of developing countries. The second question was designed based on the outcome of the first question. In this case, respondents in the first question selected 'informal payments' as the main source of corruption in Ghana's healthcare sector.

The second question then sought to ascertain from respondents the factors responsible for the use of 'informal payments' in the health sector. In this case, a list of potential factors were provided and respondents were required to select the one they believed was the lead cause. Furthermore, the field data was complemented by views of informants or experts. In particular, the study had interviews with the Ghana Anti-corruption Coalition, a famous anti-corruption civil society organization as well as two public health consultants and academics from the University of Ghana.

Finally, the study also relied on secondary data sources. These included an analysis of media content regarding reports of corruption in the health sector, reports of the Public Accounts Committee of Parliament revealing financial irregularities in the health sector and reports of the Auditor General on health sector corruption within the study time frame, thus from 2011-2020.

\subsubsection{Mode of Analysis}

Data collection instruments were systematically structured into thematic areas to ensure comprehensive coverage of specific issues and to facilitate efficient, effective and structured data capture, analysis and presentation. The interviews conducted were analyzed with a thematic focus (thematic approach). Excel spreadsheets were used for the analysis. The various responses to specific questions were entered into separate spreadsheets designed for each question. The responses were numbered, then coded and analyzed for broad thematic issues.

The format for analyzing media content on corruption scandals in the health sector was to study selected local daily newspapers and online news sources (independent of state control) from $2011-2020$. The goal was to assess which of the five thematic areas of corruption in the sector the media most consistently reported in the specified period (2011 - 2020). In relation to the Auditor General's and the Public Accounts Committee's Reports, the study examined the trend of financial improprieties contained in their annual reports from $2011-2020$ in the context of the five thematic areas under study. Similarly, the expert interviews were analyzed and situated within the context of the thematic areas of healthcare corruption under study. The reason for relying on secondary sources was to validate or otherwise the findings of the field survey.

\subsection{Findings:}

\subsection{Informal Payments}

The findings reveal that the health sector is replete with informal payments. Indeed, $40 \%$ of respondents believed that informal payments are the main drivers of petty corruption in Ghana's healthcare system. Informal payments in healthcare are payments to individuals or providers outside official payment channels, (Lewis, 2006). It takes the form of cash 'envelope' payments to physicians, pharmacists, doctors and any other official in the health sector in return for favors such as receiving preferential treatment, 'jumping queues', obtaining drugs free or lesser costs. In other words, informal payments are something in cash or kind given to supplement official payments for healthcare services (Stepurko et al. 2015).

Further, the findings have revealed that the second major source of petty corruption in Ghana's healthcare system is the admission process into various health-training institutions. In this regard, $28 \%$ of respondents believed that processes of admission into health-training schools is the cause of corruption in the health sector. The third lead cause of petty corruption, according to the findings, is procurement of drugs and supplies. Indeed, $14 \%$ of respondents chose this as the main driver of corruption in Ghana's healthcare system. In addition, socio-cultural values such as gifts giving and acts of reciprocity extended to doctors, although insignificant, contribute to corruption in the healthcare system. Thus, $10 \%$ of respondents felt these cultural norms contribute to corruption in the healthcare system.

The last issue rated by respondents is the doctor-patient ratio, and $8 \%$ of the total sample chose this as the cause of petty corruption in the healthcare system. Chart 1 below presents a summary of the findings of the first question 
on the main drivers of petty corruption in the health sector.

Chart.1 Main source of corruption in the healthcare system (\%)

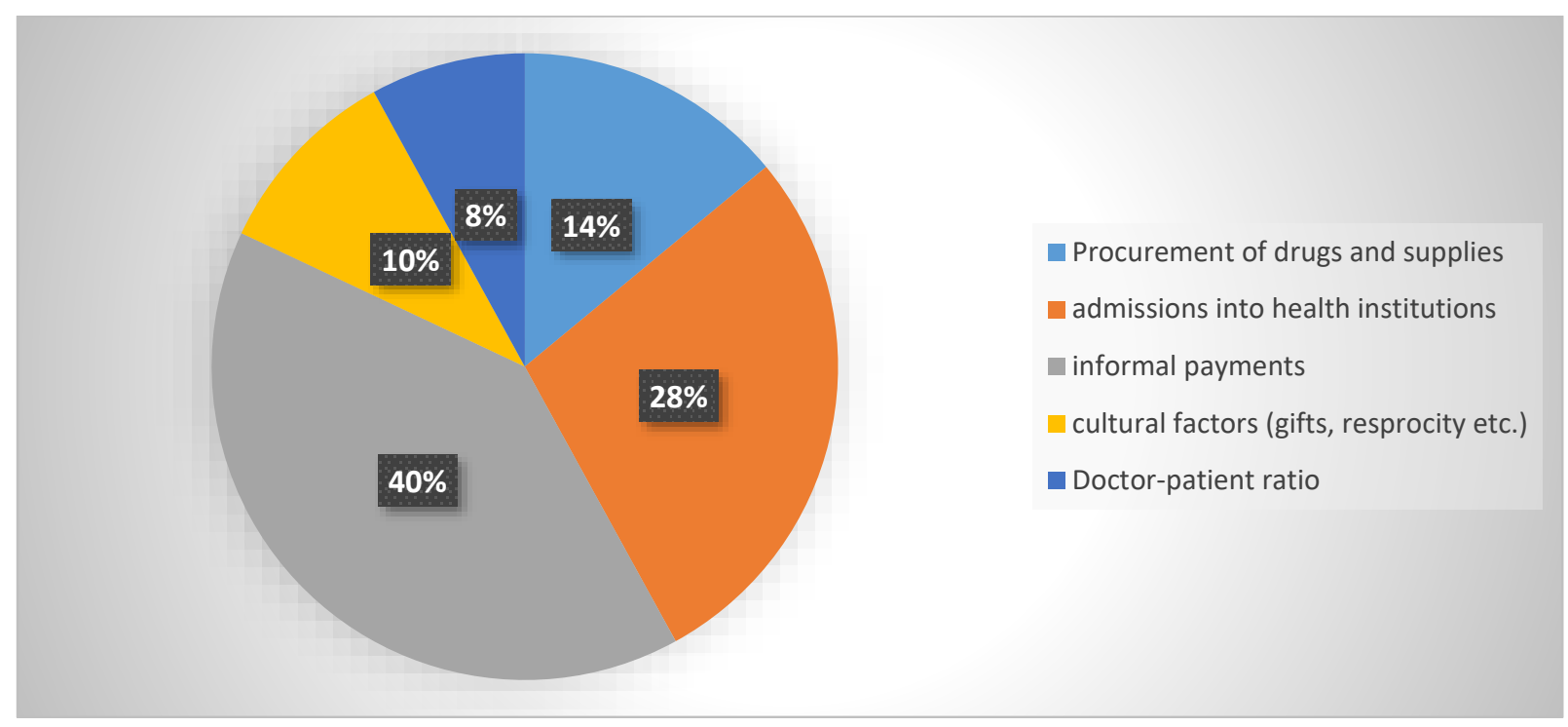

Source: Author (2022).

From the above chart, it can be observed that informal payments lead in relation to the causes of corruption in the health sector, while the least driver is the doctor-patient ratio disparity. The implication is that, just as in many other developing countries, informal payments are prevalent in Ghana's healthcare system.

\subsubsection{Preferential Treatment}

As the findings revealed informal payments to be the main drivers of corruption in the healthcare system, the study sought further to understand the factors responsible for the use of informal payments in healthcare. As in the first question, the second question was multiple-choice, embedded with four options indicating possible reasons why people make informal payments in the health sector. The difference here is that an option was provided for respondents to express their opinions if they felt strongly about an issue not captured in the questionnaire.

The findings of the survey reveal that a majority of $32 \%$ of respondents believed that the main reason for the use of informal payments is because people want to access preferential treatment when seeking medical care. Secondly, people resort to the use of informal payments because of the inability of the national health insurance scheme to cover hospital expenses. In this regard, $28 \%$ of the sample size blamed the ineffectiveness of the public health insurance for the use of informal payments in healthcare.

Thirdly, respondents felt that the habit of referring patients from public hospitals to private clinics is responsible for the use of informal payments in the health sector. In this respect, $20 \%$ of the total sample believed this practice is a contributory factor for the use of informal payments in healthcare.

Finally, $14 \%$ of the total sample size believed that the Ghanaian cultural value systems such as gift giving and acts of reciprocity do contribute to the use of informal payments in healthcare, while $6 \%$ of respondents blamed 'other' reasons for the use of informal payments. Chart 2 below provides a summary of the factors responsible for the use of informal payments in the health sector. 
Chart. 2 Reasons for the use of informal payments in healthcare (\%)

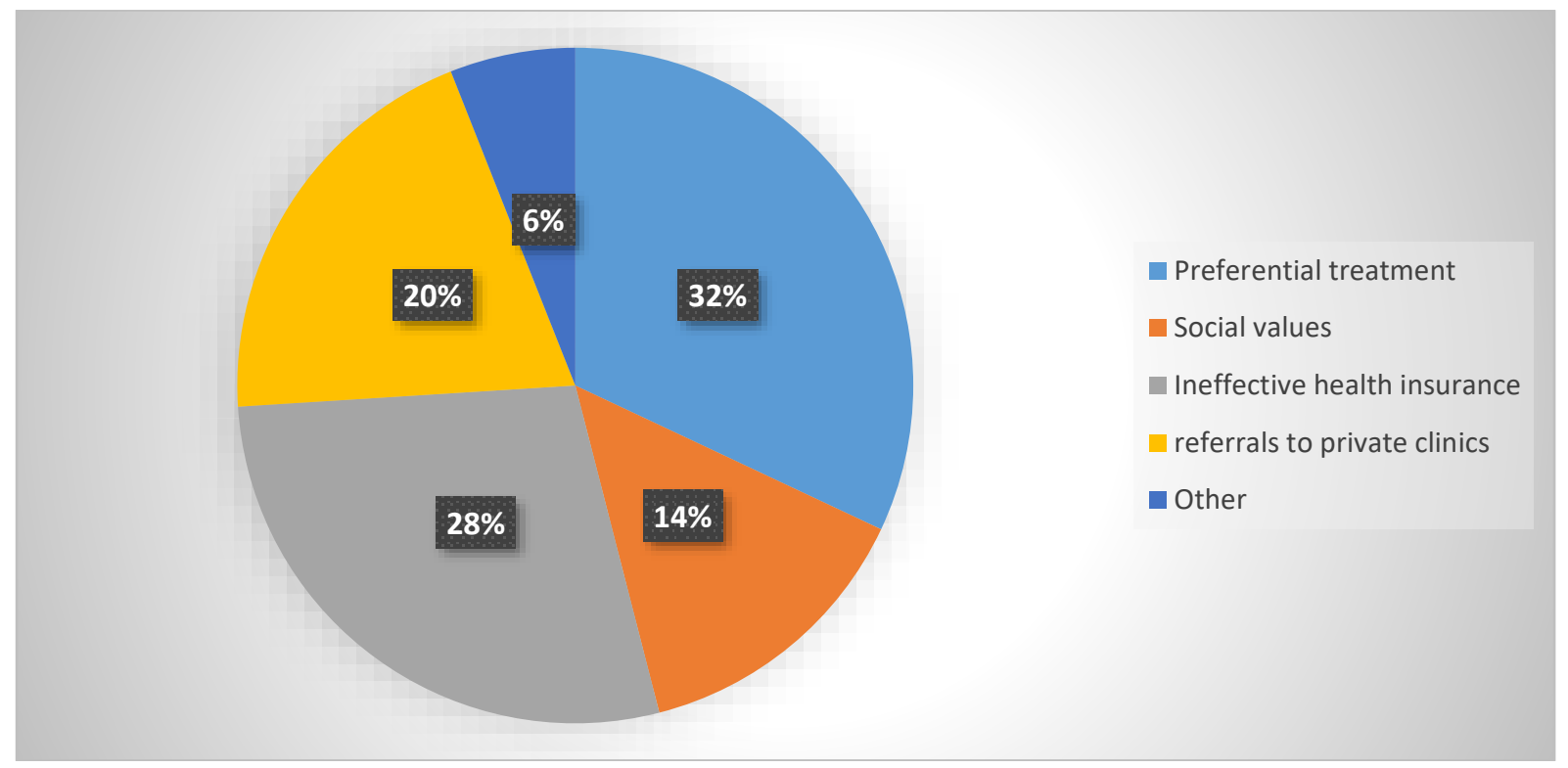

Source: Author (2022)

It can be deduced from chart 2 above that preferential treatment leads with respect to why people make informal payments in healthcare. In conclusion, the survey findings show that peoples' quest to receive preferential treatment in healthcare is the lead factor behind the use of informal payments. To ensure validity of the study, the findings of the field survey were then analyzed in the context of the expert interviews and the secondary sources. This process helped to validate or otherwise the findings of the field survey, which is needed for a holistic understanding of the real issues at hand concerning the topic under investigation.

\subsection{Discussion}

Petty corruption or bribery are small bribes paid by citizens to public officials to speed up bureaucratic processes or access to public services. Although the amounts involved are often not significant, such payments or bribes have a far-reaching impact on citizens and a corrosive long-term effect on sustainable economic growth and rule of law (Chêne, 2019). Even though corruption in healthcare is a global phenomenon, the scale is much higher in developing countries largely due to weakness in structural and administrative systems ${ }^{4}$. This study has established that corruption is replete in Ghana's healthcare system and the overarching reason informal payments lead among other factors is because people want to receive preferential treatment when seeking medical care. This practice is particularly prevalent in the urban areas where service delivery in major referral hospitals is extremely slow. In most of these referral hospitals, patients spend long hours waiting to receive medical attention and would have no hesitation paying unapproved fees to 'jump queue', a practice that perpetuates petty corruption in the health sector. Thus, patients in emergencies would be willing to offer bribes if that would facilitate immediate access to medical care at the expense of those who might have spent much longer times in a queue. The thematic areas of health sector corruption applied in this study are presented as follows.

\subsection{Health Insurance}

The primary goal of every health insurance program is to maintain and or improve the health of the subscribers by financing effective and efficient healthcare, (Faden, et al. 2011). It is no doubt that health insurance contributes significantly in pooling risks across populations by way of paying part of or absorbing the entire expenses of healthcare. Health insurance schemes absorb not only the risks of the primary subscribers but also their dependents from premiums contributed by parents, employers, government and non-governmental organizations. Therefore, the "bottom line" for uninsured people is that they are sicker and prone to die prematurely than their counterparts

\footnotetext{
${ }^{4}$ United Nations Development Programme. Fighting corruption in the health sector: methods, tools and goodpractices.www.undp.org/content/dam/undp/library/Democratic\%20Governance/IP/Anticorruption\%20Methods\%20and \%20Tools $\% 20 \mathrm{in} \% 20 \mathrm{Health} \% 20 \mathrm{Lo} \% 20$ Res $\% 20$ final.pdf
} 
who are insured. Conversely, having health coverage is associated with better health related-outcomes (Randall, et al. 2007).

It is based on the important role health insurance plays in making healthcare accessible and affordable that the government of Ghana in 2003 introduced the NHIS. In 2012, a new law, Act 852 was introduced to replace the Act 650 which sought to among other things, consolidate the NHIS, remove the administrative bottlenecks, introduce transparency, reduce opportunities for corruption and gaming of the system as well as make for effective governance of the scheme. ${ }^{5}$

The introduction of the scheme was necessitated by the challenges that came with the cash and carry policy. The cash and carry policy, which required patients including those with emergency cases to make initial payments before they could access medical services, did create so many difficulties for Ghanaians in terms of the urgency of raising money to finance treatment of the rather highly unpredictable yet unavoidable question of ill health. One corruption opportunity space under the NHIS is unwarranted reimbursement of insurance claims by service providers and some managers of the NHIS.

It occurs in such a way that managers of the scheme and the service providers collude and inflate insurance claims. The modus operandi is that the private service providers would deliberately inflate the cost of claims the National Health Insurance Authority owns them. This is done in concert with some managers of the scheme so that when the central government releases funds for reimbursement of service providers, managers and providers would then rake in the extra funds for their personal benefits.

Further, some managers of the scheme also pay money in the name of the scheme to bank accounts aside those authorized by the NHIS. Example, part of section 80 of the National Health Insurance Act provides that funds of the scheme shall be paid into such accounts as may be determined by the Council with the approval of the Controller and Accountant General.

Despite this stringent legal requirement regarding the creation of bank accounts for the collection of money meant for the scheme, some branches of the scheme work contrary to this legal requirement by creating illegal and unauthorized bank accounts. Example, the 2011 Auditor Generals' Report discovered that, the Manhyia sub-metro office of the scheme opened a new Bank Account into which payments totaling Ghe 327,170.70 were made without prior approval from the Controller and Accountant-General ${ }^{6}$. These financial irregularities include the nonexistence of receipts of monies disbursed to some service providers although monies were indeed withdrawn from the scheme's account to that effect. For example, it was discovered that an amount totaling Ghe 70, 275 as being payment made to some service providers could not be found as contained in the Auditor General's Report for $2012^{7}$.

The scheme's goal of achieving universal coverage in the near future would remain a mirage if the problem of unofficial payments persist. This is because when the insured still makes unapproved payments for healthcare, then the desire to enroll onto the policy is diminished. This can therefore defeat the objectives underlying the establishment of this social intervention.

\subsubsection{Admissions}

The admissions process into health-training institutions such as medical schools and nurses training colleges have been discovered as another avenue for corruption in the healthcare system. The findings of the survey shows that it is the second major source of corruption in Ghana's healthcare system after informal payments. Indeed, $28 \%$ of the respondents feel there is corruption in admissions to health training institutions in the country. The scramble for space in the various health-training institutions in the country is predictable because of the fact that there are only four medical schools serving many high school students who wish to study medicine in the four universities. The situation is not different in the few nursing training institutions in the country that receive thousands of applications each year and admit only a handful of them.

Application forms to the various nursing training institutions are issued by the Ministry of Health through the Human Resource Unit and subsequently dispatched to the various nursing training institutions for sale to applicants. The sale of application forms lacks transparency and is fraught with financial discrepancies as there are often cases of missing forms and other financial irregularities associated with the distribution and sale of application forms. Example, table2 below summarizes financial irregularities linked to the sale of application forms to a selected nurses training institutions for 2011 as contained in the Auditor General's Report.

\footnotetext{
5 A new law, Act 852 has replaced Act 650 in October 2012 to consolidate the NHIS, remove administrative bottlenecks, introduce transparency, reduce opportunities for corruption and gaming of the system, and make for effective governance of the scheme. Accessed from Act 852.pdf (nhis.gov.gh)

${ }^{6}$ Report of the Auditor-General on the Public Accounts of Ghana (Consolidated Fund) for the year ended 31 December 2011. Accessed from Consolidated Fund Report 2011.pdf (ghaudit.org)

7 Report of the Auditor-General on the Public Accounts of Ghana Ministries, Departments and other Agencies (MDAs) for the year ended 31 December 2012. Accessed from Ghana - Audit Report - 2012 (cabri-sbo.org)
} 
Table2. Financial irregularities in the sale of nursing training application forms

\begin{tabular}{|l|c|c|c|c|}
\hline Institution & Qty issued by HRU & $\begin{array}{c}\text { Qty received by } \\
\text { Institution }\end{array}$ & $\begin{array}{c}\text { Difference in } \\
\text { Quantity }\end{array}$ & $\begin{array}{c}\text { Value of } \\
\text { Difference }\end{array}$ \\
\hline $\begin{array}{l}\text { Cape Coast Nursing } \\
\text { Training College }\end{array}$ & 2,500 & 2,200 & 300 & 10,500 \\
\hline $\begin{array}{l}\text { Nkaful Nursing Training } \\
\text { College }\end{array}$ & 500 & 600 & 100 & 3,500 \\
\hline $\begin{array}{l}\text { Hats, Asanta NTC } \\
\text { Tamale }\end{array}$ & 1,500 & 1,000 & 200 & 7,000 \\
\hline $\begin{array}{l}\text { NMTS, Tamale } \\
\text { SOH,Tamale }\end{array}$ & 1,500 & 1,444 & 56 & 1,960 \\
\hline CHNTS,Ho & 500 & 600 & 100 & 3,500 \\
\hline MTS/HATS Mampong & 1,200 & 1,464 & 565 & 19,775 \\
\hline HATS Pantang & 500 & 950 & 250 & 8,750 \\
\hline $\begin{array}{l}\text { Public Health Nursing } \\
\text { K'bu }\end{array}$ & 1000 & 800 & 300 & 10,500 \\
\hline $\begin{array}{l}\text { Ophthalmic Nursing } \\
\text { K'bu }\end{array}$ & 1,500 & 200 & 200 & 7,000 \\
\hline NTC, Pantang & 1,600 & 1,580 & 80 & 2,800 \\
\hline Total & $\mathbf{1 4 , 4 0 0}$ & $\mathbf{1 4 , 1 1 3}$ & $\mathbf{2 8 7}$ & 2,590 \\
\hline
\end{tabular}

Source: Auditor General's Report (2011)

The table above shows the discrepancies and financial irregularities that accompany the sale of nursing training application forms to some selected nursing training colleges for the year 2011 alone. It indicates that 287 forms valued at Ghe 10,045.00 issued by the Ministry of Health to some health training institutions did not reach the supposed beneficiary institutions (AGR, 2011. Page 274). A major cause of the discrepancies in the sale of application forms is the failure of heads of health-training institutions to effectively monitor the sale of forms issued to them by the Health Ministry. These anomalies are in breach of regulation 17 of the Financial Administration Regulation of $2004,{ }^{8}$ which requires all heads of departments to ensure that all non-tax revenues are effectively collected and lodged in designated bank accounts. These inefficiencies could lead to the unofficial sale of application forms and the revenues misappropriated to the detriment of the Health Ministry.

\subsection{Cultural Factors}

In the survey findings, cultural factors placed fourth with $10 \%$ of the respondents conceding that cultural values such as gift- giving and acts of reciprocity contribute to corruption in the healthcare system. Social science research has proven that the impulse to reciprocate no matter how insignificant the gift, is a powerful influence on human's behavior as people receiving gifts are unable to remain fair and objective in their dealings. Gift-giving does not always take place out of pure appreciation. Indeed, it is a crucial way of securing quick and friendly treatment in the future because it would make the doctor think of the patient as deserving of good service (Handlos et al. 2016). In advanced economies, physicians receiving gifts from pharmaceutical representatives have the potential of

\footnotetext{
8 A Head of Department shall ensure; (a) that all non-tax revenue is efficiently collected; (b) ensure that all Non-Tax Revenue is immediately lodged in the designated Consolidated Fund Transit bank accounts. Accessed from Ghana - Public Finance Legislation - 2004 (cabri-sbo.org)
} 
increasing drug prescription by physicians to particular pharmaceutical companies. It has also been established that some drug companies go beyond the provision of gifts to sponsoring studies and seminars, skewed towards projecting their drugs. These have the potential of influencing physicians to their side in terms of drug prescription for patients.

In the specific case of Ghana and other developing countries, gifts and acts of reciprocity are highly valued in the socio-cultural settings of the people. Indeed, the Ghanaian society despises people who do not show gratitude or appreciation for the good done to them. The problem however, is how to draw a line between gifts and bribes. In this context, the patient (gift-giver) sees nothing wrong with offering a doctor something in cash or kind as a token of appreciation after a successful medical treatment. However, this could mean a form of indirect inducement for future preferential treatment. Further, cultural factors such as cronyism and nepotism do contribute indirectly to corruption in the healthcare system. In Ghanaian cultural settings, it is not out of place to give preferential treatment to close acquaintances and family members. All these promote corruption in healthcare delivery since friends and close relatives of health workers can 'jump queues' or be offered free treatment and or drugs.

\subsubsection{Procurement}

In the survey findings, respondents chose procurement and bidding for medical supplies as the third most vulnerable source of petty corruption in the healthcare system. Thus, $14 \%$ of respondents agreed that revenues meant for the health sector are lost through procurement of drugs and other supplies despite the rigid legal regime regarding procurement in the public sector. Section 43 (1) of the Public Procurement Act (Act 663) ${ }^{9}$ is clear, as it requires heads of government entities to source for as many quotations as possible, with three being the minimum in the purchase of goods and services. However, the AGR report reveals that this requirement has not been complied with in many instances in the health sector. Example, the non-compliance with the Public Procurement Act in the execution of three purchases involving an amount of GHc 5,474.85 by the District Health Administration in the Sefwi-Akontombra District had denied the health directorate any opportunity of saving money for other pressing health needs. (AGR, 2011.page 333).

Further, for Samenye health center, the center paid a whopping "amount of GHc 8,142.40 on six payment vouchers for the supply of goods and services without first requesting for at least three quotations from different sources" (AGR, 2011.page 339). Clearly, the failure of management in the Samenye Health Center to comply with the requirements of the Public Procurement Act by sourcing for at least three quotations denied the Directorate the benefits of value for money in these transactions.

In all these cases, it is obvious the Public Procurement Act, (Act 663) was never complied with in the purchase of goods and services by the health institutions indicated above. This makes it difficult to ascertain whether value for money was achieved in the purchases made. The non-compliance with the Public Procurement Act in the awards of contracts in the health sector is a recipe for corruption since sole sourcing provides a mechanism for kickbacks, revenue losses and the execution of shoddy works. It is argued that procurement corruption in healthcare is mostly due to large discretion in the process of procurement especially where the decision-making is decentralized. In this case, a decentralized procurement system can increase the probability of collusion between procurers and supplying firms (Tanzi, 1996). Thus, local officials live close to the citizens and this contiguity allows local interest groups to facilitate higher levels of corruption (Ferraresi, 2021).

\subsubsection{Doctor-Patient Ratio}

One of the factors adduced for people wanting to receive special or preferential treatment is the widening gap between the ratio of health professionals such as doctors and patients. For example, the World Health Organization doctor-patient ratio standards, which is 1:1000, thus one doctor for one thousand patients is illusive. Indeed, the World Bank's survey in 2017 placed Ghana at $14^{\text {th }}$ in sub-Saharan Africa and $4^{\text {th }}$ in West Africa respectively. ${ }^{10}$ The doctor- patient disparity is worst in rural areas especially the northern parts of the country where health personnel refuse postings. Example, it is estimated that one doctor attends to 29,000 patients in the Upper East and West Regions, while a single doctor attends to 44,000 patients in the Northern Region (Chronicle, October 8 , 2013).

One would therefore assume that the acute shortage of health professionals in most parts of rural areas in the country contributes to the phenomenon of informal payments in healthcare. A patient seeking treatment where

\footnotetext{
${ }_{9}$ Procedure for request for quotation 43. (1) The procurement entity shall request quotations from as many suppliers or contractors as practicable, but from at least three different sources. Public Procurement Act - PPA Ghana

10 The World Bank's survey from 2015 and 2017 and still valid and applicable indicates that Ghana is 14th in sub-Saharan Africa in terms of doctor to patient ratio. Accessed from World Bank Report: Ghana ranks 14th in doctor-to-patient ratio in $\underline{\text { sub-Saharan Africa } \mid \text { Pulse Ghana. Physicians (per 1,000 people) - Ghana } \mid \text { Data (worldbank.org) }}$
} 
there is shortage of doctors, beds, nurses and machines may have to offer a bribe or will pay for it, if asked, because the person needs access to treatment (Teremetskyi et al. 2020b).

\subsection{The Way Forward}

\section{Bureaucratic processes and remuneration gaps}

Among the key motivating factors for the use of informal payments is insufficient remuneration and salaries for doctors and health workers in general. Further, as a result of bureaucratic processes, it takes not less than two years for newly recruited health workers to be validated by the Ministry of Finance and the Controller and Accountant General's Department before they begin to receive salaries. In tackling these, there is the need for a review of differences in the salary structure among health sector workers in particular and the fairness and adequacy of public sector compensation policies in the country as a whole. Government agencies should as well embrace the current government digitization agenda to remove the bureaucratic bottlenecks on clearance and validation processes of newly recruited workers. More to the point, salary gaps can be addressed through short-term measures such as increasing the financial and performance accountability of the official fee system or internally generated funds. This would enable hospitals to retain sufficient revenue that can be used to pay newly posted health workers whose salaries are still being processed. This will reduce the demands for informal payments and for that matter petty corruption in healthcare. This strategy, which was implemented in Cambodia, has helped to reduce the incidence of informal payments in healthcare (Vian, 2005).

\section{Formal guidelines for gifts and acts of reciprocity}

Petty corruption in healthcare can be reduced where there is a formal procedure in accepting gifts by patients as a form of appreciation since there is a thin-line between gifts and bribes. Studies have shown that the line between gifts and bribes is too blurred such that gifts may be used to entice providers' future care-giving behavior. The anticipation of receiving gifts could even have an influence on provider's decisions. While gifts are inherent in the Ghanaian cultural values, formal procedures need to be established by policy-makers with details on the quantum and value of gifts to be accepted and ways in which people can show appreciation to doctors through the institutions (hospitals) rather than individuals. Thus, collective gifting fulfills the social or moral obligation while reducing the problematic incentive the gift might represent.

\section{A revamped and effective health insurance regime}

A major problem with the national health insurance is the failure on the part of the government to reimburse service providers on time. The delays in reimbursement of claims to service providers have contributed to rendering the public insurance ineffective to deliver its core mandate of making healthcare affordable, particularly to the poor and socially disadvantaged. The ineffectiveness of the national health insurance scheme occasioned by late or nonreimbursement of insurance claims by the government have led to situations whereby subscribers of the scheme receive either incomplete medical care, denied medications or services.

A strengthened and effective health insurance regime can contribute to the reduction of petty corruption in health and informal payments since it limits the use of cash flows. As such, if policy-makers desire to eliminate petty corruption in the sector, then the national health insurance scheme needs to be resourced appropriately so that health providers receive timely reimbursement. The national health insurance authority needs to improve upon its monitoring and oversight roles in order to track and check managers who conspire with service providers to demand undue claims from the government, thereby depriving the scheme of much needed resources to function effectively.

\section{Capacities of health training institutions}

On the issue of corruption in admissions into health training institutions, one of the ways that could be used to promote transparency in this process is the need for the Ministry of Health to audit these institutions periodically to know their capacities to enroll students each academic year. The periodic audits will help not only ascertain whether students admitted have requisite qualifications but also, whether admissions are done according to advertised capacities.

\section{Bridging the Doctor-Patient Ratio}

For the Doctor-Patient ratio disparity, the Ministry of Health should consider introducing an incentive system that would encourage doctors in particular, to accept postings to deprived communities. This could be in the form of extra allowances for those working in rural areas especially in the northern parts of the country. This would motivate doctors and other health workers to work in rural settings and as such, reduce the doctor-patient ratio disparity that will in turn eliminate the need for bribes to be offered in order to access healthcare. 


\subsection{Conclusion}

The study has unearthed the main driver(s) of petty corruption in a healthcare system. The focus on petty corruption is particularly significant due to the scant scholarly attention given to it, which is driven by the assumption that a reduction in grand corruption would have a knock-on effect on petty corruption (Carr \& Jago, 2014). This study therefore advances scholarly work on corruption in healthcare systems as it provides a unique case on how corruption is manifested, particularly from the perspectives of patients. The specific contribution of the study to the field is that it has brought to light the lead drivers of petty corruption in a healthcare system and the factors fueling it in a developing country context.

The study is however limited by the fact that it did not incorporate the views of doctors, physicians and other health workers in the survey. For a holistic understanding of the drivers and consequences of petty corruption in healthcare, future research should therefore include the views of these stakeholders to strengthen the evidence for generalizability to be made on this research problem.

\section{References}

Amundsen, I. (1999). Political corruption: An introduction to the issues. Chr. Michelsen Institute. http//www.cmi.no 1999-7.PDF (cmi.no)

Azfar, O., Gurgur, T. (2008). Does corruption affect health outcomes in the Philippines? Econ Gov 9, $197-$ 244.https://doi.org/10.1007/s10101-006-0031-y

Balboa, J., \& Medalla, E.M. (2006). Anti-corruption and governance: The Philippine experience. In APEC Study Center Consortium Conference (pp. 1-28).

Belli, P., Gotsadze, G., \& Shahriari, H. (2004). Out-of-pocket and informal payments in health sector: evidence from Georgia. Health Policy, 70(1), 109-123. DOI: 10.1016/j.healthpol.2004.03.007

Bovbjerg, R., \& Hadley, J. (2007). Why health insurance is important. Health Policy Briefs. The Urban Institute. Washington, $D C$

Bussell, J. (2012). Corruption and Reform in India: Public Services in the Digital Age. Cambridge University Press. DOI: https://doi.org/10.1017/S1537592714002527

Carr, I., \& Jago, R. (2014). Petty corruption, development and information technology as an antidote. The Round Table, 103(5), 465-482. DOI: 10.1080/00358533.2014.966495

Chattopadhyay, S. (2013). Corruption in healthcare and medicine: Why should physicians and bioethicists care and what should they do. Indian J Med Ethics, 10(3), 153-9. DOI: 10.20529/IJME.2013.049

Chêne, M. (2019). Successful approaches to tackle petty corruption. Transparency International. http://www.jstor.com/stable/resrep20474

Faden, L., Vialle-Valentin, C., Ross-Degnan, D., \& Wagner, A. (2011). Active pharmaceutical management strategies of health insurance systems to improve cost-effective use of medicines in low-and middleincome countries: a systematic review of current evidence. Health Policy, 100(2-3), 134-143.

Fazekas, M., Tóth, I. J., \& King, L. P. (2013). Anatomy of grand corruption: A composite corruption risk index based on objective data. Corruption Research Center Budapest Working Papers No. CRCB-WP/2013, 2. DOI: $10.2139 /$ ssrn.2331980

Ferraresi, M., Gucciardi, G., \& Rizzo, L. (2021). Savings from public procurement centralization in the healthcare system. European Journal of Political Economy, 66, 101963.

Ferrinho, P., Omar, M. C., de Jesus Fernandes, M., Blaise, P., Bugalho, A. M., \& Van Lerberghe, W. (2004). Pilfering for survival: how health workers use access to drugs as a coping strategy. Human Resources for Health, 2(1), 1-6. DOI: 10.1186/1478-4491-2-4

Ghanaian Chronicle, (October 8, 2013). The Worsening Doctor-Patient Ratio. The Ghanaian Chronicle. Retrieved from: The Worsening Doctor-Patient Ratio ... (modernghana.com)

Horodnic, A. V., Mazilu, S., \& Oprea, L. (2018). Drivers behind widespread informal payments in the Romanian public health care system: from tolerance to corruption to socio-economic and spatial patterns. The International Journal of Health Planning and Management, 33(2), e597-e611. DOI: 10.1002/hpm.2509

Hussmann, K. (2011). Vulnerabilities to Corruption in the Health Sector: Perspectives from Latin American SubSystems for the Poor. United Nations Development Programme. Panama.

Jain, A. K. (Ed.). (2001). The political economy of corruption(Vol. 2). Routledge. https://doi.org/10.4324/9780203468388

Lambsdorff, J. G. (2007). The institutional economics of corruption and reform: Theory, evidence and policy. Cambridge University Press. DOI: 10.1017/CBO9780511492617 
Lewis, M. (2006). Governance and corruption in public health care systems. Center for Global Development working paper, (78). DOI: 10.2139/ssrn.984046

Matukhno, N. (2014). Varieties of corruption: Differential causes and consequences. The University of Arizona. http://hdl.handle.net/10150/325420

Neerup Handlos, L., Fog Olwig, K., Bygbjerg, I.C., \& Norredam, M. (2016). Return Migrants' Experience of Access to Care in Corrupt Healthcare Systems: The Bosnian Example. International Journal of Environmental Research and Public Health, 13(9), 924.

Pilbeam, C., Alvarez, G., \& Wilson, H. (2012). The governance of supply networks: a systematic literature review. Supply Chain Management: An International Journal, 17(4), 358-376.

Pilbeam, C., Alvarez, G. and Wilson, H. (2012), "The governance of supply networks: a systematic literature review", Supply Chain Management, Vol. $17 \quad$ No. $4, \quad$ pp. 358376. https://doi.org/10.1108/13598541211246512

Reginato, E., Fadda, I., Poletti, P., \& Pavan, A. (2020). Informal payments and performance in the healthcare sector: Possible relationship in a sub-national perspective. International Journal of Business and Management. Vol. 15.http://hdl.handle.net/11584/294416.

Rose-Ackerman, S. (1999a). Corruption and government: Causes, consequences, and reform. Cambridge University Press: Doi.org/10.1017/CBO9781139175098

Rose-Ackerman, S., \& Palifka, B. J. (2016). Corruption and government: Causes, consequences, and reform. Cambridge University Press. DOI: 10.1017/CBO9781139962933

Savedoff, W. D. (2007). Transparency and corruption in the health sector: a conceptual framework and ideas for action in Latin American and the Caribbean. Washington DC: Inter-American Development Bank.

Savedoff, W. D., \& Hussmann, K. (2006). Why are health systems prone to corruption? Global Corruption Report 2006. Global Corruption Report 2006: Corruption and... - Transparency.org

Stepurko, T., Pavlova, M., Gryga, I., \& Groot, W. (2015). Making patients pay: informal patient payments in Central and Eastern European countries. Frontiers in public health, 3, 192. https://doi.org/10.3389/fpubh.2015.00192

Tanzi, V. (1996). Review of Some Efficiency and Macroeconomic Aspects. In Annual World Bank Conference on Development Economics 1995 (p. 317). World Bank Publications.

Teremetskyi V, Duliba Y, Kroitor V, Korchak N, Makarenko O. (2021). Corruption and strengthening anticorruption efforts in healthcare during the pandemic of Covid-19. Medico-Legal Journal: 25-28(1) Doi: $10.1177 / 0025817220971925$

Thompson, Dennis F. (2018). "Theories of Institutional Corruption.” Annual Review of Political Science 21 (1): 495-513. Doi: 10.1146/annurev-polisci-120117-110316

Tranfield, D., Denyer, D. and Smart, P. (2003) Towards a Methodology for Developing Evidence: Informed Management Knowledge by Means of Systematic Review. British Journal of Management, 14, $207-222$. http://dx.doi.org/10.1111/1467-8551.00375

Vian, T. (2008). Review of corruption in the health sector: theory, methods and interventions. Health policy and planning, 23(2), 83-94. DOI: 10.1093/heapol/czm048 